\title{
Personal Radiotoxicological (First Aid) Kit
}

\author{
GACHÁLYI András, GYULAI Gábor ${ }^{1}$
}

\begin{abstract}
In recent years, with the spread of nuclear industrial activities, and the widespread use of radioactive materials and products the possibility of radionuclide contami-nation of humans and animals has significantly increased. During nuclear tests or reactor accidents, a large amount of radioactive materi-als may enter the environment which can contaminate the living environment (air, water, vegetation, soil), for a long period. This contamination may enter living or- ganisms by inhalation, intake and ingestion, causing severe biological damage. As an example the Chernobyl reactor accident can be mentioned, where there was no possibility for the decorporation of isotopes, as there were no products available such as the "RADISTOP".

To achieve appropriate decorporating (and decontaminating) treatment which is effective, it is highly recommendable to use a personal Radiotoxicological First Aid Kit (PRK) within the shortest possible time after internal contamination. This unit provides effective treatment to decorporate the most common incorporated fission products.
\end{abstract}

\section{Introduction}

Nuclear testing, nuclear accidents (e.g. Chernobyl) or incidents caused by natural disasters (like Fukushima), as well as terrorist attacks can cause the radioactive contamination of the environment. The living media (air, water, vegetation, soil) can become contaminated for a long period, and serious biological damage can be caused to living organisms. The situation is similar to the threat caused by chemical plants, or the heavy metal pollution caused by increasingly heavy traffic. The whole body is exposed to the contamination caused by toxic heavy metals and radioisotopes, which incorporate into various organs (bone, liver, thyroid, etc.) where they can pose health hazards (e.g. toxic, carcinogenic) long after the incorpora- tion.

For effective treatment and handling of the aforementioned problems there have not been any available products present on the market and as such nor have they been available for the Hungarian Armed Forces.

The authors of this article present a special first aid kit, the Personal Radiotoxicological Kit (PRK) and its compounds.

\section{The reasons for developing the products}

Of late, as a result of urbanization and the development of the industry we need to be pre- pared for more severe contamination of the environment. Emerging environmental contami-

1 gabor.gy@ citromail.hu 
nants (radioactive and/or toxic metals, hazardous waste, etc.) are either directly or indirectly (e.g. through the food chain) a potential danger to persons executing there work in these areas, as well as the local population.

As regards the polluting effects of the radioactive isotopes generated in nuclear fission, mainly $\mathrm{Sr}-90, \mathrm{Zr}-95, \mathrm{Nb}-95$, $\mathrm{Ru}-106, \mathrm{I}-131, \mathrm{Cs}-137, \mathrm{Ce}-144$ as well as the U-235 and $\mathrm{Pu}-239$ play an important role during the initial period of the fallout. During the latter period the long-term fallout fission products, such as Sr-90, Cs-137, pose a potential threat.

The Toxicology Research and Radiobiology Research Departments of the Scientific Insti- tute (Health Protection Institute of the Home Defence Forces) in cooperation with the Min- istry of Defence Military Technology Institute (respectively its successors), based on inter- national recommendations, and their own research, have developed and complied a Personal Radiotoxicological Kit, which includes all the drugs and the application methods meeting the requirements of the decorporation procedures.

The components of the kit can not only be used as a personal Radiotoxicological Kit, but they can also be made available on the pharmaceutical market individually.

The Personal Radiotoxicological (First Aid) Kit has been developed for emergency treat- ment of personnel contamination by inhalation or ingestion of iodine, strontium caesium, rare earths, plutonium, transplutonics, and a mixture of fission products; as well as for the decontamination of already contaminated wounds with the above mentioned substances.

The Personal Radiotoxicological (First Aid) Kit was given a bronze medal at the Geneva International Innovation Salon, and it was also given the Grand Prize at the International Exhibition of Genius Inventions. (shown in Figure 5 and 6) The Personal Radiotoxicological (First Aid) Kit was put into service for the Hungarian Army in 2011.

The kit contains different types of substances according to the different areas of intended use.

Table 1. The Personal Radiotoxicological (First Aid) Kit should contain the following components

\begin{tabular}{|c|c|c|c|c|c|c|}
\hline \multicolumn{2}{|l|}{ Item } & \multirow{2}{*}{$\begin{array}{l}\text { Agents } \\
\begin{array}{l}\text { Potassium } \\
\text { iodide }\end{array}\end{array}$} & \multirow{2}{*}{$\begin{array}{l}\text { Quantity } \\
\begin{array}{c}\text { (100 mg of } \\
\text { iodide) }\end{array}\end{array}$} & \multirow{2}{*}{$\begin{array}{l}\text { Format and Package } \\
\text { Tablet in foil package }\end{array}$} & \multirow{2}{*}{$\begin{array}{c}\begin{array}{c}\text { Total } \\
\text { (piece) }\end{array} \\
3\end{array}$} & \multirow{2}{*}{$\begin{array}{c}\begin{array}{c}\text { Expiry } \\
\text { date } \\
\text { (year) }\end{array} \\
2\end{array}$} \\
\hline $\begin{array}{l}1 . \\
(\mathrm{KI})\end{array}$ & Jodecorp & & & & & \\
\hline $\begin{array}{l}. \\
\text { (DK1A) }\end{array}$ & Radecorp & $\begin{array}{c}\mathrm{Na}-\mathrm{CaDTPA}- \\
\text { salt }\end{array}$ & $0,54 \mathrm{~g}$ & Inhalation aerosol & 2 & 2 \\
\hline $\begin{array}{l}3 . \\
\text { (DK1B) }\end{array}$ & Radecorp & $\begin{array}{c}\mathrm{Na}-\mathrm{CaDTPA}- \\
\text { salt }\end{array}$ & $0,50 \mathrm{~g}$ & $\begin{array}{c}10 \mathrm{ml} \text { liquid in plastic } \\
\text { bottle }(10 \mathrm{ml})\end{array}$ & 1 & 5 \\
\hline $\begin{array}{l}4 . \\
\text { (DK2) }\end{array}$ & Radistop & Prussian-blue & $1 \mathrm{~g}$ & Paste in Tube (10 g) & 1 & 5 \\
\hline $\begin{array}{l}5 . \\
\text { (DK3) }\end{array}$ & Raditox & Pectin * & $5 \mathrm{~g}$ & $\begin{array}{c}\text { Powder in foil pack- } \\
\text { age }\end{array}$ & 1 & 5 \\
\hline
\end{tabular}

* Natural high molecular weight polysaccharide 
1.) JODECORP — tablet:

Using potassium iodide tablets, taken orally, reduces the accumulation of thyroid iodine isotopes and helps to accelerate excretion of the radioisotope. [1]

2.) RADECORP - inhalation aerosol:

Pentasodium hydrogen bis (calcium pentetate) inhalation aerosol as a chelating com- pound binds and therefore reduces the absorption of consumed rare earth metals (e.g. cerium) and transuranium (e.g. plutonium), and it also increases their excretion. [2]

3.) RADECORP - topical solution:

Pentasodium hydrogen bis (calcium pentetate) solution can cleanse isotopically contam- inated wounds and their surroundings. As a complexing compound this solution binds and thus reduces the possibility of the absorption of the rare earth metals (e.g. cerium) and trans- uranium (e.g. plutonium) through the injured skin. [2]

4.) RADISTOP — oral suspension:

Prussian blue10 $\mathrm{ml}$ paste (white sealed capped PE tube) taken orally effectively reduces the absorption of radioactive caesium isotopes (e.g., Cs-134, Cs-137) in the body (lessening the amount of deposition) and increases the exertion rate of isotopes. [3]

5.) RADITOX — powder taken orally:

A defined composition, special pectin powder product (in alu-alu foil pouch), which dis- solved in water turns into gel, should be taken orally. It primarily inhibits the absorption of the radioactive strontium and various radioactive and / or toxic metals (such as cadmium, mercury, lead, etc.) in the body (reducing the deposition rate), and increases the rate of ex- cretion of contaminants. [4]

Table 2. Instruction for the users of the Personal Radiotoxicological (First Aid) Kit

\begin{tabular}{|l|l|l|l|}
\hline Label & Radionuclide & \multicolumn{1}{|l|}{ Type of contamination } \\
\hline 1. & Iodine & Wound & Ingestion or inhalation \\
\hline $\begin{array}{l}\text { 2. } \\
3 .\end{array}$ & $\begin{array}{l}\text { Rare earths } \\
\text { Transuranium }\end{array}$ & $\begin{array}{l}\text { Wash the wound Radecorp } \\
\text { (3) solution }\end{array}$ & $\begin{array}{l}\text { Inhale Radecorp (2) } \\
\text { (if necessary repeated } \\
\text { transmission) }\end{array}$ \\
\hline 4. & Caesium isotopes & $\begin{array}{l}\text { 1 tube Radistop was (perhaps mixed with a little water) } \\
\text { directly into the(up 3x1tube/ days) }\end{array}$ \\
\hline 5. & Strontium isotopes & $\begin{array}{l}\text { Swallow 1 bag Raditox mixed with a little water (up to } \\
\text { 3x1 bag / day) }\end{array}$ \\
\hline \multicolumn{2}{|l|}{ Mixture of fission products } & $\begin{array}{l}\text { Continue all instructions for 1-5 days depending on the } \\
\text { type of contamination }\end{array}$ \\
\hline
\end{tabular}


The body of the Personal Radiotoxicological (First Aid) Kit and the pharmaceutical inventory (medication set) of $1-4$. shown in Pictures.

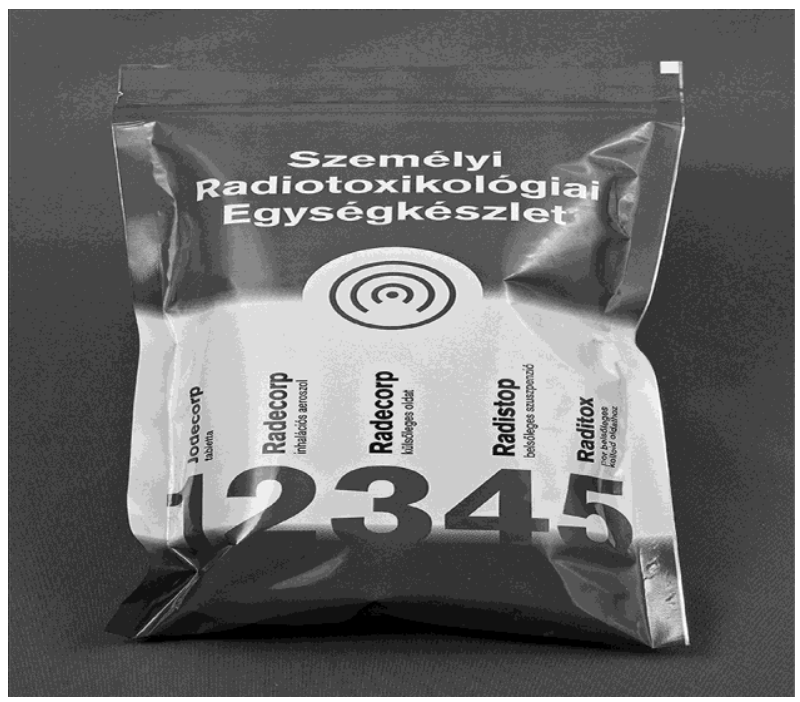

Picture 1. Personal Radiotoxicological (First Aid) kit external form

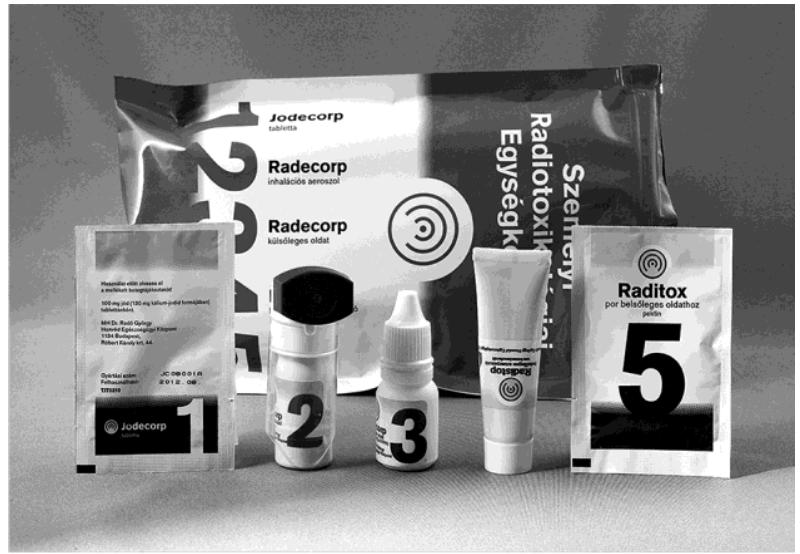

Picture 2. Personal Radiotoxicological (First Aid) kits health (medicament) products 


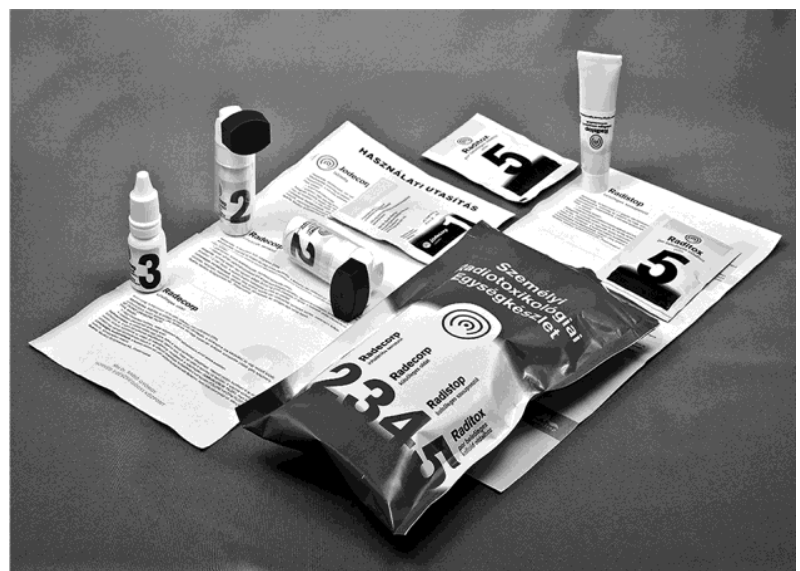

Picture 3. Personal Radiotoxicological (First Aid) kits health (medicament) products

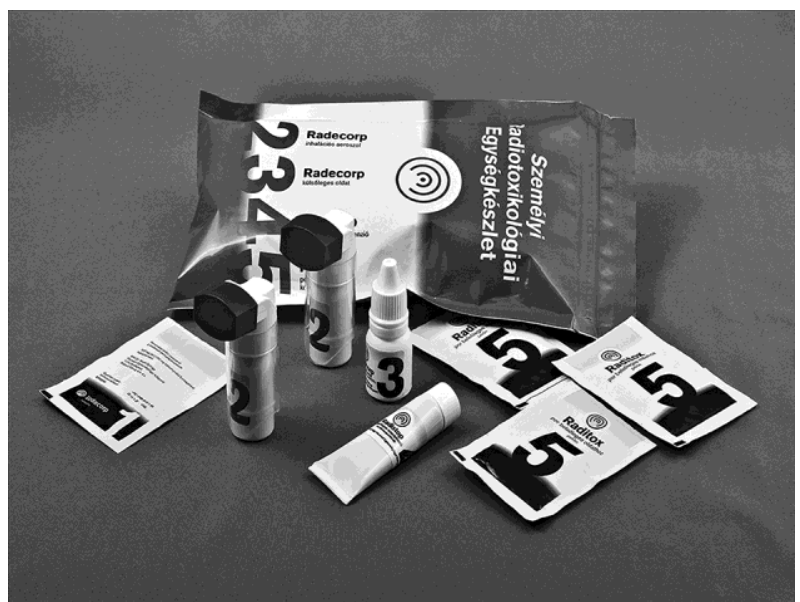

Picture 4. Personal Radiotoxicological (First Aid) kits health (medicament) products 


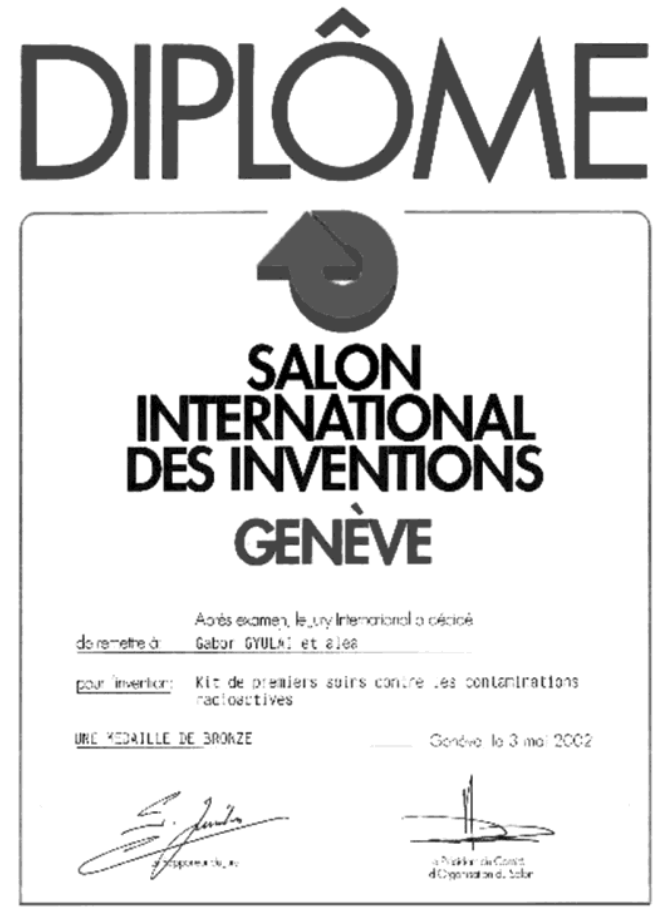

Picture 5. Geneva International Innovation Award

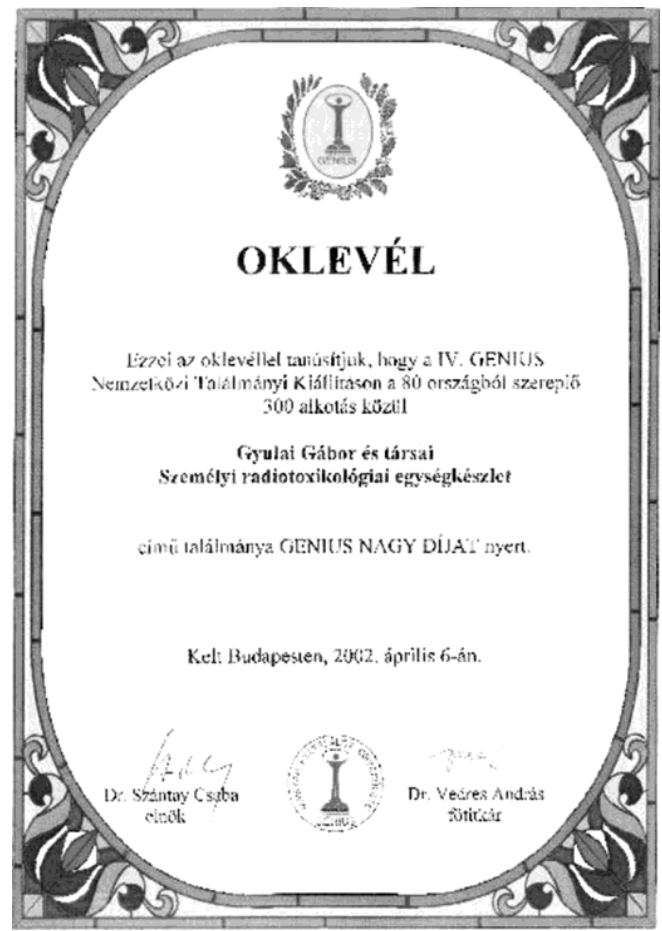

Picture 6. International Exhibition of Inventions Genius Grand Prize 
The main application areas of Personal Radiotoxicological (First Aid) Kit

a) The nuclear power industry

\section{Nuclear testing, reactor accidents}

Once radionuclides have entered the body (mainly by inhalation, or digestion or through wounds) they quickly get into the bloodstream reaching their final place of deposition. Con- sequently for effective treatment it is essential to start the detoxification process as soon as possible. The immediate usage of the Personal Radiotoxicological (First Aid) Kit makes this rapid treatment possible, enhancing the effectiveness of the applied methods.

\section{Maintenance and rescue operations}

In these cases, the primary task is to prevent any external and internal contamination, aim- ing to prevent or reduce the contact of the radioactive material with the body or its ingestion.

Maintaining relevant health and technical safety regulations - such as the use of individ- ual and collective protection equipment, instrument control, possibility of immediate decon- tamination or prophylactic medication is essential. The immediate application of the Personal Radiotoxicological (First Aid) Kit can contribute to the success of this process.

The Personal Radiotoxicological kit contains all the ingredients and treatment methods which are necessary for the prophylactic treatment of the population at risk, as well as the possible therapeutic treatment of post-intoxication.

b) Research, diagnosis, therapy area

During the performance of the above mentioned activities one of the most important tasks is to prevent accidental/incidental internal and external contamination. Both the personnel involved and the patients receiving the treatment are to wear the necessary protective equip- ment and keep the safety regulations. The use of the Personal Radiotoxicological (First Aid) Kit provides both prophylactic and therapeutic drug management options.

c) Acts of terrorism

Terrorist acts (e.g. the Tokyo subway gas poisoning, September $11^{\text {th }}$ attacks in the US.) clearly demonstrated that the world should be prepared for unexpected events, which are likely to be unavoidable. To prevent or to reduce personal and property damage caused by unavoidable terrorist attacks it is necessary to have a well prepared and competent body of professionals, with adequate financial and technical support. To achieve these goals is both an important national and international interest.

d) Local wars

In this case, primarily different terrorist attacks (e.g. anti-government rebellions in Syria or ethnic riots) should be taken into consideration.

e) Other (e.g. natural disaster) cases

These events include damage caused by natural disasters (earthquakes, floods, hurricanes, etc.), or accidents (e.g. Fukushima reactor accident). Chemical plants, and the environmental pollution caused by heavy traffic also pose a potential threat. 


\section{Conclusions and recommendations}

During the operation of the nuclear energy industry, and nuclear explosions the external and internal radiation exposure (fall-out fission) and the possibility of incorporation is to be reckoned with at all times.

It is advisable, therefore, for all parties potentially involved in possible radioactive con- tamination to possess or to have access to a Personal Radiotoxicological Kit for self-help. The user of the kit may also be able to provide further help to those exposed to contamination.

In the following years, further research tasks are deemed necessary to develop therapeutic procedures, which ensure higher levels of health care (medical aid facilities, hospitals). This research should enhance the efficacy of decorporation of the radioactive and/or inactive toxic metals, also in the case of mixed metals they should determine the effective and appropriate medical treatment.

\section{References}

[1] BÁRDOS A., DÁVID Á. Z., FÜRÉSZ J., GACHÁLYI A., GYULAI G., NAGY L., NAMÉNYI J. (2001): Delayed release, stabilized iodide salt tablets for the preparation of radioiodine contamination evacuation. NSZO: A61K-049/00

[2] BENKÓCZY Z., FÜRÉSZ J., GACHÁLYI A., GYULAI G., NAGY L., NAMÉNYI J.(2001): Pentasodium hydrogen bis (diethylene triamino-penta acetic acid, calcium), and this compound, for removing the radioactive fission products and the non-radioactive toxic metals suitable compositions. NSZO: A61K-049/00

[3] BENKÓCZY Z., FÜRÉSZ J., GACHÁLYI A., GYULAI G., NAGY L., NAMÉNYI J., ÖSZI ZS. (2001): Aqueous suspension composition and method for its preparation. NSZO: A61K-033/26; C07F-015/02

[4] DÁVID Á., FÜRÉSZ J., GACHÁLYI A., GÁL L., GYULAI G., HIDEG J. (2001): Material mixture contains pectin and hydrophobic colloidal silica, processed for its preparation and application of radioactive fission products and/or toxic metal removal from the living body. NSZO: A61K-049/00 